If, on the other hand, a suspended particle of dimensions double that of a molecule of starch be considered, the fraction of the hemisphere ASB (Fig. 2) which would be occupied by the suspended particle would be five-eighths, and would include all that part of it where any effective component in the direction CS could be developed, so that the resultant acting on a molecule of the surrounding liquid at $\mathrm{C}$ in this case would be considerably more than five-eighths of the full internal pressure at a plane surface.

From such considerations it is clear that in passing from molecules of the dimensions estimated for those that give true solutions to molecules of the size that is compatible only with colloidal solution, if the relation between these dimensions and the radius of the sphere of molecular attraction is such as has been presented, a very great change in the behaviour of a solvent such as water must be observed. Considering only, as has been done in this letter, the relations between the molecules of solvent, the force tending to withdraw these molecules from the surface of molecules of solute will be found to increase eightthousandfold. The large molecules must be far more unstably dispersed than the small. As soon as they come within a distance of each other which is less than the radius of attraction for the solvent, they will be forced together by the internal pressure of the solvent.

The force tending to remove a molecule of solvent from the surface of a particle roo $\AA$. in diameter $>\frac{5}{8}$ say $=75$ per cent. of the internal pressure at a plane surface; a starch molecule $50 \AA$. in diameter $>\frac{1}{4}$ say $=33$ per cent.; a molecule $25 \AA$. in diameter $>1 / 32$ say $=5$ per cent.; a $\mathrm{CO}_{2}$ molecule $2.5 \AA$. in diameter $>\mathrm{r} / 32000$ sav $=0.005$ per cent.

In this consideration of the conditions obtaining in solutions no account obviously has been taken of any forces except those in play between the molecules of solvent. The supposition of such forces carries with it the supposition also of similar forces acting between molecules of solute, and especially, too, between them and the molecules of solvent. When there is no attraction between solute and solvent, even the small residuum of unbalanced internal pressure which a particle leaves free to act on the molecules of the dispersing medium when its dimensions are as small as those assigned to the molecule of carbon dioxide must result in its joining up with others of its kindin fact, in its being insoluble. The difficulty that such considerations taken by themselves leave untouched is the difference between the finite degrees of solubility peculiar to each kind of substance capable of dissolving in a solvent.

The University, Sheffield.

\section{Oceanographic Research in the British Empire.}

Ix the interesting leading article in Nature of March Io, and in the discussion which preceded it, one method of conducting oceanographic research appears to have been practically ignored. We mean its encouragement in permanent institutions and by continued marine surveys in the diverse parts of the British Empire. You have rightly laid stress on the importance of intensive study in particular localities, but we doubt whether research of the kind can be carried out in a satisfactory manner by parties detached for limited periods of time from an expedition of world-wide scope. There is nothing that has struck us more in our own work on the Indian seas and lagoons than the importance of returning again and again to the same place to investigate special nroblems. For exampie, in the investigation of the fauna of the Chilka Lake, a small offshoot of the No. 2683 , VOL. IO7]
Bay of Bengal, now being completed by the Zoological Survey of India, the true character of the fauna is being elucidated only by returning year after year and month after month to the same hunting-grounds; and it is not only the fauna to which this applies, for we find that the hydrography also must be studied again and again in years of different climatic conditions and at all seasons. The Chilka Lake is only a minute, almost isolated, fragment of the ocean, but in order to obtain a solid basis for the working out of any oceanographic problem recurrence is necessary, not only because conditions change from time to time -and in many parts of the ocean they change, so far as we know, very little--but also because detailed work on results obtained in the field inevitably opens new vistas, suggests unsuspected sources of error, and reveals paths that ought to be followed out.

We would suggest, therefore, the possibility of giving further encouragement to local oceanographic investigations. Such investigations have hitherto been very largely, though by no means exclusively, of a faunistic nature; for example, Dr. Gilchrist's work on the seas of Africa, that of the Australian Fisheries Department, and last, but not least, that of the R.I.M.S. Investigator in Indian seas. There is no reason, however, except the lack of physicists, to use the term in a broad sense, why this should be so, and even zoology, not to mention botany, still offers an unlimited scope for oceanographers. War has interfered with the work of the Investigator, but we have every reason to hope that her scientific researches will shortly be resumed under conditions more satisfactory than ever before, and that for at ieast one month every year the work of the ship will be devoted to purely scientific research. The Madras Fisheries Department already possesses a small marine laboratory in the Gulf of Manaar, and we hope that the Zoological Survey of India will shortly be in a position to open a larger one in the Andaman Islands, the seas round which, perhaps, offer as good opportunities for oceanographic investigations of all kinds as any seas in the world. The interest of the Government of India in work of the kind is proved by the fact that the post of Surgeon-Naturalist to the Marine Survey of India has been in existence since 1875 . Shortly before the war the trustees of the Indian Museum, with the approval of the Government, consulted the leading marine biologists throughout the world as to the advisability of granting increased facilities to the Surgeon-Naturalist, and the Government accepted the practically unanimous verdict of the experts by voting additional grants, etc. It has only been the war that has interfered with its generous proposals. We are not acquainted with details as to the encouragement given to oceanographic research in the Dominions, but the instances we have already cited are sufficient to prove that it has not entirely lacked svmpathy, even if only from a strictly practical point of view.

Would it not. perhaps, be more feasible to approach the different Governments of the British Empire, which abuts on the seas of all the world, to organise, with the aid of the experts in their employment, separate but co-ordinate research rather than to attempt to set on foot a single colossal expedition the cost of which is admitted at present to be prohibitive, while its course could not be permanent, or, indeed, extend for more than a comparatively few years?

\section{N. Annandate,}

Director. Zoological Survev of India.

R. B. Seymour Sewell,

Surgeon-Naturalist to the Marine Survey of India.

Royal Societies' Club, St. James's Street. 